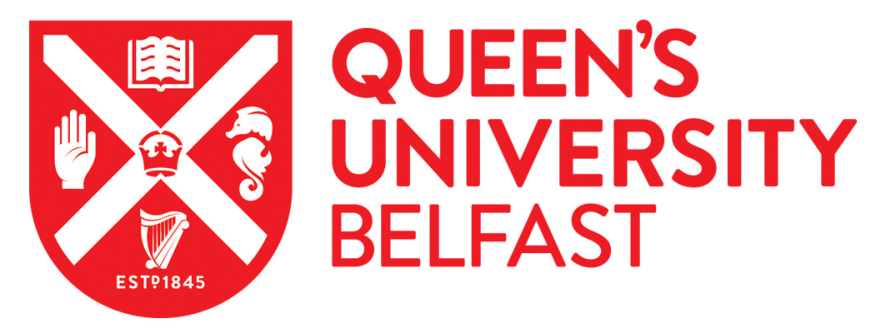

\title{
Mechanical testing methods for drug-releasing vaginal rings
}

McCoy, C. F., Millar, B. G., Murphy, D. J., Blanda, W., Hansraj, B., Devlin, B., Malcolm, R. K., \& Boyd, P. (2019). Mechanical testing methods for drug-releasing vaginal rings. International Journal of Pharmaceutics, 559, 182191. https://doi.org/10.1016/j.ijpharm.2019.01.026

\section{Published in:}

International Journal of Pharmaceutics

\section{Document Version:}

Peer reviewed version

\section{Queen's University Belfast - Research Portal:}

Link to publication record in Queen's University Belfast Research Portal

\section{Publisher rights}

Copyright 2019 Elsevier.

This manuscript is distributed under a Creative Commons Attribution-NonCommercial-NoDerivs License

(https://creativecommons.org/licenses/by-nc-nd/4.0/), which permits distribution and reproduction for non-commercial purposes, provided the author and source are cited.

\section{General rights}

Copyright for the publications made accessible via the Queen's University Belfast Research Portal is retained by the author(s) and / or other copyright owners and it is a condition of accessing these publications that users recognise and abide by the legal requirements associated with these rights.

Take down policy

The Research Portal is Queen's institutional repository that provides access to Queen's research output. Every effort has been made to ensure that content in the Research Portal does not infringe any person's rights, or applicable UK laws. If you discover content in the Research Portal that you believe breaches copyright or violates any law, please contact openaccess@qub.ac.uk. 


\section{Accepted Manuscript}

Mechanical testing methods for drug-releasing vaginal rings

Clare F. McCoy, Bronagh G. Millar, Diarmaid J. Murphy, Wendy Blanda,

Bashir Hansraj, Brid Devlin, R. Karl Malcolm, Peter Boyd

PII:

S0378-5173(19)30061-4

DOI:

https://doi.org/10.1016/j.ijpharm.2019.01.026

Reference: $\quad$ IJP 18088

To appear in: $\quad$ International Journal of Pharmaceutics

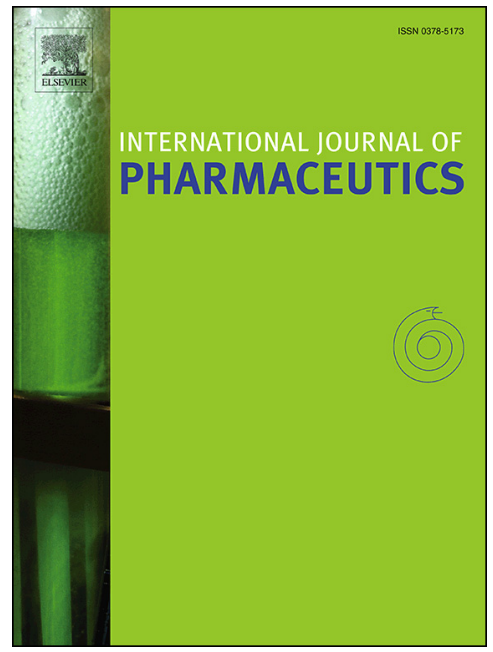

Received Date: $\quad 20$ September 2018

Revised Date: $\quad 23$ December 2018

Accepted Date: $\quad 12$ January 2019

Please cite this article as: C.F. McCoy, B.G. Millar, D.J. Murphy, W. Blanda, B. Hansraj, B. Devlin, R. Karl Malcolm, P. Boyd, Mechanical testing methods for drug-releasing vaginal rings, International Journal of Pharmaceutics (2019), doi: https://doi.org/10.1016/j.ijpharm.2019.01.026

This is a PDF file of an unedited manuscript that has been accepted for publication. As a service to our customers we are providing this early version of the manuscript. The manuscript will undergo copyediting, typesetting, and review of the resulting proof before it is published in its final form. Please note that during the production process errors may be discovered which could affect the content, and all legal disclaimers that apply to the journal pertain. 


\title{
Mechanical testing methods for drug-releasing vaginal rings
}

\author{
Clare F. McCoy ${ }^{1}$, Bronagh G. Millar ${ }^{3}$, Diarmaid J. Murphy ${ }^{1}$, \\ Wendy Blanda ${ }^{2}$, Bashir Hansraj $^{2}$, Brid Devlin $^{2}$, R. Karl Malcolm ${ }^{1}$, Peter Boyd ${ }^{1} *$ \\ ${ }^{1}$ School of Pharmacy, Queen's University Belfast, Belfast BT9 7BL, UK \\ ${ }^{2}$ International Partnership for Microbicides, Silver Spring, MD 20910, USA
}

${ }^{3}$ School of Mechanical and Aerospace Engineering, Queen's University Belfast, Belfast BT9 5AH, UK

*Corresponding author. Tel: +44 (0)28 9097 2623; Fax: +44 (0)28 9024 7794;

E-mail: p.boyd@qub.ac.uk

Keywords: ISO, ASTM method; compression test; tensile test; intravaginal ring; 


\begin{abstract}
Vaginal rings (VRs) are currently marketed for contraceptive or hormone regulation purposes, and investigationally, have been widely reported for delivery of antiretrovirals to reduce HIV transmission. To date, there is no national or international standard for the mechanical testing and minimum performance characteristics of any VR based products. Here, we describe a a series of mechanical tests examining the durometer hardness, static and dynamic compression response, tensile properties and twist resistance of vaginal rings. The tests were conducted on currently marketed VRs and a number of the International Partnership for Microbicides' (IPM) investigational VR formulations. With wider application in the field, the tests described herein could form the basis for a more standardised approach to the mechanical testing of VRs.
\end{abstract}




\section{INTRODUCTION}

Vaginal rings (VRs) are flexible polymeric devices used for sustained or controlled release of drug molecules to the human vagina for clinical benefit. Six vaginal ring products are currently marketed - Estring $^{\circledR}$ (Pfizer Inc., USA), Nuvaring ${ }^{\circledR}$ (Merck \& Co., USA), Femring ${ }^{\circledR}$ (Actavis, UK), Fertiring ${ }^{\circledR}$ (Laboratorios Silesia, Chile), Progering ${ }^{\circledR}$ (Laboratorios Silesia, Chile), Ornibel ${ }^{\circledR}$ (Exeltis Healthcare, Spain) - all offering long-acting release of one or more steroidal compounds for either contraception or hormone replacement therapy (Friend, 2011; Malcolm et al., 2016, 2012). A seventh ring product - Annovera ${ }^{\mathrm{TM}}$ - offering long-acting release of the contraceptive hormones, Nestorone ${ }^{\circledR}$ and ethinyl estradiol, for a period of 1 year has recently been approved by the U.S. Food and Drug Agency (FDA) and is expected to be commercially available in late 2019 or early 2020. Interest in VR technology has surged in the last ten years, mostly due to extensive developments around antiretroviral-releasing rings for reduced sexual transmission of human immunodeficiency virus (HIV) (Baum et al., 2012; Fetherston et al., 2013b; Johnson et al., 2012; Moss et al., 2016). One such microbicidal ring device - the dapivirine (DPV) silicone elastomer vaginal ring - is currently under review for approval by the European Medicines Agency (EMA). Numerous other combination microbicide and multipurpose prevention technology (MPT) rings - capable of simultaneously releasing both a microbicide and a hormonal contraceptive agent - are also in preclinical or early clinical development (Boyd et al., 2016; Ugaonkar et al., 2015), including a novel pod-type IVR capable of delivering the antiretroviral tenofovir disproxil fumarate alone or in combination with emtricitabine and maraviroc (Vincent et al., 2018). More recently, a vaginal ring designed to provide controlled release of the cervical ripening agents isosorbide mononitrate and misoprostol singly or in combination has been reported (Wang et al., 2018). 
Recently in the U.S., the FDA's Center for Drug Evaluation and Research (CDER) and the Center for Devices and Radiological Health $(\mathrm{CDRH})$ have stated that all new drug-releasing intravaginal rings - which are considered a combination of a drug product and a medical device - should be classified as a "vaginal system". With no international standards currently available describing acceptable mechanical properties for VR drug delivery products, CDER has published non-binding recommendations for industry regarding vaginal drug product specifications. With specific reference to the development of microbicide-releasing vaginal rings for HIV prevention, the FDA guidance describes a requirement for a 'mechanical integrity test including tensile strength for vaginal rings' (FDA, 2014). Here, mechanical integrity implies that a device should perform its function in a safe, reliable and environmentally resistive manner. VRs, which are typically positioned high in the vagina by the user, are constantly exposed to the damp mucus-coated epithelial surfaces of the vaginal canal, with an estimated vaginal fluid volume of 1-2 mL (Owen and Katz, 1999). Additionally, they are in a state of permanent compression mainly from the muscularis layer that supports the vaginal structure (Kim, 2015). The forces experienced by VRs in situ are not well characterised, with previous studies focussing on the biomechanics of the human vagina from the perspective of fibromuscular tissues in the vaginal wall (Bisplinghoff et al., 2012; Conrad et al., 2017; Eberhart et al., 2017) and how these change with the effects of age, pregnancy, prolapse and menopause (Baah-Dwomoh et al., 2016; Chantereau et al., 2014; Jean-Charles et al., 2010; Rahn et al., 2008). More direct methods for in vivo pressure measurements within the vaginal cavity have been conducted (Rubod et al., 2006), although specific pressure values were not reported.

Assessment of the mechanical performance of vaginal ring devices is an essential part of the design process, particularly in understanding the effects of different elastomer choices on ring 
performance. While it is important to consider the physical characteristics of VRs from a functional perspective, the role of this testing in assessing previously established acceptance criteria or for quality control (QC) purposes is equally important. Testing should be conducted to evaluate a wide range of mechanical parameters, including durometer, tensile strength, elongation at break, compression strength, fatigue due to cyclic loading, seal integrity following cyclic loading or bond strength (for rings with cores or pods inserted into the ring body) and aging studies to determine changes to the mechanical properties with time.

To date, various different testing methods have been used to assess the mechanical properties of a range of VRs designs. However, with no VR mechanical testing standard available, researchers and VR developers have limited guidance regarding the mechanical testing protocols required by regulatory agencies. Durometer hardness testing carried out to ASTM D2240 (“ASTM D2240-15e1, Standard Test Method for Rubber Property — Durometer Hardness," 2015) is the international standard for measuring the hardness of rubber and plastic materials, and can be used to assess the impact of quality of the incoming raw materials and the performance of the final product. Durometer hardness is not fully indicative of final mechanical characteristic of a VR design, since the drug loading, the physical nature of the incorporated drug, the type of polymer material used and the ring dimensions also have a significant impact. However, it can be used as an effective and relatively simple quality control test for simple silicone elastomer matrix-type ring devices. Durometer hardness testing has previously been reported for VRs (Pathak et al., 2014), although non-standard indenter and sample geometries and non-ASTM methods were used.

Compression testing is one of the most commonly applied methods to assess the mechanical properties of VRs. Typically, the VR is held such that it has a single degree of freedom, with 
its lowest point - viewed axially - resting in a grooved or flat rigid surface while the diametrically opposite end is acted upon by a stressing force at a controlled deformation rate until a defined strain is achieved (where strain is defined as the maximum force to achieve the desired strain). For example, segmented TPU VRs containing tenofovir (TFV) and dapivirine - compressed to $27 \mathrm{~mm}$ (50\% of their initial outer diameter (OD)) - required $2.5 \mathrm{~N}$ of force (Johnson et al., 2010); silicone elastomer pod rings required $1.25 \mathrm{~N}$ to achieve compression of 55-85\% of their original OD (Baum et al., 2012); and silicone elastomer rings containing maraviroc and dapivirine required $2.0 \mathrm{~N}$ of force to compress them to 50 $\mathrm{mm}(90 \%$ of their original OD) (Fetherston et al., 2013a).

While compression testing mimics the forces experienced by VRs in clinical use, tensile elongation is also commonly used as a test method to assess the ultimate tensile strength of a VR device and is particularly important for complex VR designs that include weld joints, pods or drug-loaded inserts. For example, tensile testing is currently used as a low burden QC test for NuvaRing ${ }^{\circledR}$ to assess weld joint integrity on product release. Tensile testing is also routinely used to re-evaluate ring products following re-supply of and/or changes to the manufacturing materials. Tensile tests may also reflect VR removal from the vagina, where a user hooks a finger around the inner diameter and pulls firmly to remove the device. When a VR has one or more radial joints, assessment of the tensile strength is crucial (Johnson et al., 2010). Trying to identify a suitable design space for vaginal ring mechanical characteristics is challenging, particularly given the limited research into understanding the forces to which a vaginal ring would be subjected during normal handling and clinical use. Rings that are too large or too inflexible can cause damage to the vaginal tissue, as has been previously been observed with incorrect use of some pessaries (Bash, 2000). With respect to the ultimate tensile strength required for a VR, this would come from the unlikely scenario where a ring 
was stuck rigidly in the vaginal canal, whilst the women was trying to remove it, i.e. able to exert the maximum pull force using a fingertip. To place this value in perspective, an ergonomic study examining finger strengths of female subjects reported maximum pull forces of $109.7 \mathrm{~N}$ (SD 28.1, $\mathrm{n}=40$ ), on a $51.0 \mathrm{~mm}$ diameter ring with $7.0 \mathrm{~mm}$ cross sectional diameter (CSD), reducing to $94.5 \mathrm{~N}(\mathrm{SD} 28.7, \mathrm{n}=40)$ for a $24.0 \mathrm{~mm}$ OD ring with $4.0 \mathrm{~mm}$ CSD (Cort and Potvin, 2011). In both experiments, the rings were fabricated from a rigid material and remained in a fixed circular geometry throughout the test. In a clinical scenario, elastomeric VRs would deform axially when pulled during removal, practically negating the feasibility of having a VR stuck in the vaginal canal under the action of pulling (tensile elongation). This is an area where further clinical study is required to precisely measure the tensile force exerted on an elastomeric ring during removal from the vagina.

A number of groups have performed mechanical analysis of new vaginal ring formulations as part of their experimental development (Baum et al., 2012; Clark et al., 2014, 2012; Fetherston et al., 2013b). However, to date, rational and methodical mechanical analysis including comparison with commercially available VRs - has not been reported. Here, in accordance with the CDER guidelines (FDA, 2014), we report a series of mechanical testing methods for VRs based on ISO 8009:2014 "Mechanical contraceptives - Reusable natural and silicone rubber contraceptive diaphragms - Requirements and tests" (ISO, 2014). These methods have been used to assess compressional and tensile strength of various commercial and experimental VRs. It should be noted that contraceptive diaphragms are typically dome/cup-shaped devices molded from a natural or silicone elastomer rubber that contain an encased wire spring and for this reason behave differently to silicone elastomer or thermoplastic VR devices. To account for these differences in design, many of the tests outlined in ISO 8009:2014 have been significantly modified here for use with VRs. 


\section{Materials and methods}

\subsection{Materials}

Micronised dapivirine (DPV) was supplied by S.A. Ajinomoto OmniChem n.v. (Wetteren, Belgium). Non-micronised levonorgestrel (LNG) was supplied by Chemo Industriale Chimica s.r.l. (Saronno, Italy). Medical grade, addition-cure silicone elastomers MED-4870 and DDU-4320, and MED-360 silicone oil were supplied by NuSil ${ }^{\mathrm{TM}}$ Technology Inc. (Carpinteria, CA, USA). DPV (25 mg) rings (Batch No.: NK513, RF599, SC521) were supplied by International Partnership for Microbicides (IPM). NuvaRing ${ }^{\circledR}$ (Merck Sharp \& Dohme Ltd., Hertfordshire, UK), Femring ${ }^{\circledR}$ (Warner Chilcott Ltd., Larne, UK) and Estring ${ }^{\circledR}$ (Pfizer Ltd., Kent, UK) were purchased from a local community pharmacist under a research supply agreement with Queen's University Belfast.

\subsection{Vaginal ring manufacture}

Matrix-type silicone elastomer VRs containing either DPV (200 mg) in MED-4870 silicone elastomer (Boyd et al,, 2016), or DPV (200 mg) and LNG (320 mg) (200/320 mg DPV+LNG) in DDU-4320 silicone elastomer were manufactured using a Babyplast $^{\mathrm{TM}}$ 6/10P injection molding machine (Chronoplast, Spain) fitted with custom, stainless steel, singlecavity injection molds. DPV MED-4870 Part A premixes were prepared by accurately weighing appropriate quantities of MED-4870 silicone elastomer, MED-360 silicone oil (to aid dispersal of the DPV) and DPV into a screw-cap polypropylene container. The materials were mixed at $3000 \mathrm{rpm}$ for $3 \mathrm{~min}$ in a DAC-150 FVZ-K Speedmixer ${ }^{\mathrm{TM}}$ (Hauschild, Germany) followed by a manual scrape down step and further speedmixing at $3000 \mathrm{rpm}$ for 10 s. Part B premixes were prepared using the same protocol. DPV+LNG DDU-4320 Part A premixes were prepared by accurately weighing appropriate quantities of DDU-4320, DPV and LNG into a sealable Speedmixer ${ }^{\mathrm{TM}}$ container before mixing at $2350 \mathrm{rpm}$ for $30 \mathrm{~s}$ in a 
DAC-600.2 VAC.P Speedmixer ${ }^{\mathrm{TM}}$ (Hauschild, Germany) followed by a manual scrape down step and further speedmixing at $2350 \mathrm{rpm}$ for $30 \mathrm{~s}$. A final hand-mix step was performed to ensure that any material adhering to the sides of the container was fully incorporated into the elastomer mix. Part B premixes were prepared using the same protocol. Premixes were stored at $4{ }^{\circ} \mathrm{C}$ until use. Immediately prior to injection molding, equal portions of Part A and Part B MED-4870 premixes were sequentially transferred to a large screw-cap plastic container until $\sim 400 \mathrm{~g}$ total had been transferred. The material was hand-mixed for $30 \mathrm{~s}$, speedmixed at 2350 rpm for $30 \mathrm{~s}$ and further speedmixed for $60 \mathrm{~s}$ at $1800 \mathrm{rpm}$. For DDU-4320 premixes, equal portions of Part A and Part B DDU-4320 premixes were added to a large plastic container and speedmixed at $2350 \mathrm{rpm}$ for $30 \mathrm{~s}$ followed by a $30 \mathrm{~s}$ hand-mix to ensure that all of the material was fully incorporated. Once mixed, the silicone elastomer materials were transferred to a SEMCO injection cartridge designed for use with the dosing system on the Babyplast $^{\mathrm{TM}}$ injection molder. MED-4870 and DDU-4320 rings were manufactured using cure conditions of $185^{\circ} \mathrm{C}$ for $60 \mathrm{~s}$ and $100^{\circ} \mathrm{C}$ for $90 \mathrm{~s}$, respectively.

\subsection{Characterisation of ring geometry}

Ring weight, cross-sectional diameter and outer diameter were measured for eight VR formulations (Table 1). Digital callipers (RS Components, UK) were used for assessment of CSD and OD. Care was taken to ensure that the VRs were not compressed or distorted during measurement. NuvaRing ${ }^{\circledR}$ was noticeably ovoidal in shape, rather than toroidal, a consequence of its extrude-and-weld manufacturing process. Therefore, care was taken to orientate NuvaRing ${ }^{\circledR}$ in the callipers in a similar manner for each measurement (so as not to record minimum or maximum diameter) to ensure measurement of the OD was consistent across the ring batch. 


\subsection{Durometer testing}

The durometer value depends on a number of factors, including: (i) the type of material being tested, (ii) the geometry of the indentor, (iii) the pressure exerted, (iv) the thickness of the test sample, and (v) the rate of increase of pressure. The durometer of the raw silicone elastomer materials and ring formulations was tested according to the material Certificate of Analysis (CoA) using ASTM D2240 (Type A scale) (“ASTM D2240-15e1, Standard Test Method for Rubber Property — Durometer Hardness," 2015). For accuracy, the silicone elastomer test materials were required to be flat and of sufficient size to ensure edge effects could not influence the measurement. A custom aluminium slab mold (dimensions: $102 \times 102 \times 6 \mathrm{~mm}$; $\mathrm{w} \times 1 \times \mathrm{d}$ ) was designed and manufactured to enable reproducible sample production (Fig. 1). Both API-loaded and API-free silicone elastomer slabs were evaluated. API-free sample preparation involved mixing the equal amounts of either MED-4870 silicone elastomer Part A and Part B or DDU-4320 silicone elastomer Part A and Part B in a DAC-150 FVZ-K Speedmixer ${ }^{\mathrm{TM}}$ at $3000 \mathrm{rpm}$ for $30 \mathrm{~s}$ to ensure homogeneity before transfer of the mixed material to the custom slab mold. DPV-loaded MED-4870 elastomer slab samples were prepared by dispersing either $0.3125 \% \mathrm{w} / \mathrm{w}$ or $2.5 \% \mathrm{w} / \mathrm{w}$ DPV (loadings equivalent to $25 \mathrm{mg}$ and $200 \mathrm{mg}$ of DPV in an $8 \mathrm{~g}$ vaginal ring device) in the MED-4870 silicone elastomer. DPV+LNG loaded DDU-4320 slabs were prepared by dispersing $2.56 \% \mathrm{w} / \mathrm{w}$ DPV and $4.10 \% \mathrm{w} / \mathrm{w}$ LNG (equivalent to $200 \mathrm{mg}$ DPV and $320 \mathrm{mg} \mathrm{LNG}$ in a $7.8 \mathrm{~g}$ vaginal ring) in the DDU-4320 silicone elastomer. MED-4870 samples were cured in a heated compression mold using either the cure conditions outlined in the $\mathrm{NuSil}^{\mathrm{TM}}$ MED-4870 product specification $\left(65^{\circ} \mathrm{C}\right.$ for $\left.5 \mathrm{~min}\right)$ or standard DPV ring manufacturing conditions $\left(185^{\circ} \mathrm{C}\right.$ for $\left.60 \mathrm{~s}\right)$. DDU4320 samples were cured using either the conditions outlined in the product specification (80 $\pm 5^{\circ} \mathrm{C}$ for $3 \pm 1 \mathrm{~min}$ ) or standard $200 / 320 \mathrm{mg}$ DPV+LNG ring manufacturing conditions $\left(100^{\circ} \mathrm{C}\right.$ for $\left.90 \mathrm{~s}\right)$. Samples were allowed to stabilize for $24 \pm 1 \mathrm{hr}$ at ambient temperature 
before durometer testing was performed. Each slab was placed on a hard, flat surface prior to testing with a Sauter HBA 100-0 graduated dial durometer (Sauter, Switzerland) calibrated for Shore A hardness (arbitrary units). Six individual measurements per elastomer slab were recorded making sure that all measurements were at least $12 \mathrm{~mm}$ from any boundary so as to avoid any influence from edge effects and at least $6 \mathrm{~mm}$ from any other test point. Durometer testing was also performed on the eight VR types (Table $1, n=13$ replicates per type) using either a Sauter HBA 100-1 graduated dial durometer (Shore A scale) or Checkline RX-DD-M digital durometer (Shore M scale) held in an OS-3 stand (Checkline Europe, Birmingham, UK). Each ring was placed on a hard, flat surface prior to testing. Four individual measurements per ring were recorded. Although Shore A hardness testing of ring samples does not strictly comply with the ASTM D2240 standard due to the curved surface of the samples and possible influence of edge effects, it can a useful investigational tool for comparison of vaginal ring formulations. For example, in silicone elastomer VR formulations with large cross-sectional diameters, Shore A hardness measurements have been shown to be accurate and can be successfully used for quality control purposes. However, Shore M hardness gauges are specifically designed for use with samples that cannot be accurately measured using a Shore A gauge due to either the sample geometry or thickness of the test sample.

\subsection{Static 28-day deformation testing}

Vaginal ring devices are typically designed to remain in situ for periods in excess of 28-days. For this reason, the effects of continual compression on the degree of ring recovery and the potential for structural failure of the eight VR devices (Table 1; $n=13$ rings per type) over a 28-day period were evaluated using custom-designed and manufactured compression jigs capable of compressing ring devices of different dimensions to $25 \pm 5 \%$ of their original OD. 
The $25 \pm 5 \%$ compression criterion was selected from the current industry standard for compression testing of diaphragm devices (ISO, 2014). Test rings were individually placed in a chamber of a custom aluminium compression jig and secured with a Perspex ${ }^{\circledR}$ cover. A central screw acting as a single point load was inserted into each chamber and the ring compressed to $25 \pm 5 \%$ of its OD for a 28 -day period (Fig. 2A-D). Due to differences in the ring geometries of the eight formulations being tested, some ring groups could not be compressed to $25 \pm 5 \%$ of their OD due to their CSD dimensions. Where compression to $25 \%$ of the outer diameter could not be achieved, the rings were compressed until the internal ring sides touched. For all other ring formulations, the internal ring sides did not touch during compression. After 28-days, each ring was removed from the compression jig and allowed to recover for a period of 15-20 s (to ensure consistency of ring response across all formulations following removal of the compression force) before the percentage recovery of the original ring diameter was assessed using a series of ring recovery gauges (Fig. 3A). The use of ring gauges rather than measured OD, using digital callipers, was selected as the preferred method of assessing ring recovery as it enabled immediate, consistent and rapid assessment of all ring groups upon removal from the compression jig. Each ring was placed on an appropriate ring gauge with the bottom edge of the ring lined up with the horizontal line on the gauge (Fig. 3B). The position of the top edge of the ring on the gauge indicated the percentage recovery in terms of the original OD.

\subsection{Determination of ring tensile properties}

Tensile testing was performed for the eight different vaginal ring types ( $\mathrm{n}=13$ rings per type) using an Instron Universal Testing System (Instron Model 5564, UK) in tension mode fitted with a $2000 \mathrm{~N}$ load cell and Merlin software control. Specifically, designed pin grips (Fig. 4) were fabricated to minimise localized stress concentrations during testing. VRs were placed 
around the upper and lower ring grips, which had been adjusted for the internal diameter of each ring batch so that the rings were placed just in tension. Each ring was stretched using a test speed/grip separation speed of $500 \pm 50 \mathrm{~mm} / \mathrm{min}$ until fracture of the ring was achieved. Tensile extension at maximum load $(\mathrm{mm})$ and maximum load at maximum tensile extension (N) were recorded for all rings. As NuvaRing ${ }^{\circledR}$ samples were circumferentially ovoidal rather than toroidal in shape and contained an obvious weld joint, these rings required placement over the ring grips so that the weld joint was positioned at $90^{\circ}$ to the vertical plane. Percent elongation at break values for individual rings were determined using Eqn.1.

Eqn. 1.

$$
\% \text { elongation at break }=\left(\frac{\text { max.extension at max.load }(\mathrm{mm})}{\text { ring internal diameter }(\mathrm{mm})}\right) \times 100
$$

\subsection{0-cycle compression testing}

The compressional strength of IPM's 25 mg DPV Ring-004 vaginal ring device (currently undergoing regulatory review) at product release is evaluated by compression of the ring through a distance of $5 \mathrm{~mm}$ ( $\mathrm{n}=6$ compressions per ring) using a texture analyser and the average force (N) for compression recorded (Fetherston et al., 2013b). This method is primarily a quality control check to demonstrate that the silicone elastomer has cured properly. The mechanical strength and durability of diaphragm devices involves a test during which the diaphragms must be compressed to $25 \pm 5 \%$ of their original OD and released 1000 times with recovery acceptance criteria set as at least $90 \%$ recovery of the original diaphragm diameter (ISO, 2014). In this study, a series of custom ring holders, capable of holding multiple rings simultaneously, were designed and fabricated for use with a TA texture analyser (TA-XTPlus, Stable Microsystems, UK) fitted with a $30 \mathrm{Kg}$ load cell and Texture 
Exponent (TEE32) 32 software. An aluminium plate with multiple rectangular grooves (7 or 13 grooves per plate) into which the VRs loosely sit was mounted on the lower fixed platform of the TA (Figs. 5A and C). An upper Perspex ${ }^{\circledR}$ plate with identical grooves, mounted on the upper moveable arm of the TA (so the centrelines of lower and upper grooves were aligned), was lowered until it touched the top of the rings so that all rings were held in a vertical position with slight pre-compression. Rings ( $\mathrm{n}=13$ per formulation) were cyclically compressed from $100 \%$ to $25 \pm 5 \%$ of their original OD (Figs. 5B and D), 1000 times using the following general test parameters: Target Mode - Distance; Distance - 27-39 $\mathrm{mm}$ (varies according to ring geometry); Test Speed $-15 \mathrm{~mm} \mathrm{~s}^{-1}$; Count 1000. For those rings that could not be compressed to $25 \pm 5 \%$ of their OD due to their larger CSD, the rings were compressed until the ring sides touched. After the 1000th compression cycle, rings were removed from the custom holder and visually inspected for obvious signs of deterioration. Ring diameters were assessed using the ring gauges (Fig. 3A) and expressed as a percentage recovery of the original outer ring diameter. Due to the number of rings being evaluated in a single test cycle (6-13 rings), it was not feasible to test ring recoveries immediately after removal of the compression force. For this reason, OD recovery measurements for all rings were made within $15 \mathrm{~min}$ of completion of the test cycle.

\subsection{Twisting during compression testing}

The current industry standard for diaphragm devices (ISO, 2014) requires that the degree of twist of diaphragms during compression be assessed to ensure that the devices are not significantly deformed when compressed using forces similar to those exerted during device insertion. For twist during compression testing of VRs having differing geometries, a custom twist measurement jig was designed and fabricated (Fig. 6). The custom twist-tester fits to a TA and consists of a lower Perspex ${ }^{\circledR}$ ring holder, available in different sizes according to the 
CSD of the ring under test, with an indicating pointer. This holder is fitted onto a floating shaft, axially held by a low friction bearing, set into a Perspex ${ }^{\circledR}$ base plate with $360^{\circ}$ of angular graduations marked every $5^{\circ}$. The base plate is attached to the TA via the standard mounting fixture points. The top of the ring is held in a non-rotating grooved Perspex ${ }^{\circledR}$ plate attached to the crosshead of the TA. In operation, the top of the ring is rotationally fixed while the bottom of the ring is able to rotate freely as the ring is compressed via the movement of the TA crosshead. Rings were mounted as shown in Fig. 6B and compressed by lowering the TA cross-arm so that the distance between the lower ring mount and the crossarm was in accordance with diaphragm twist-test parameters as stated in Annex $\mathrm{F}$ of ISO8009:2014 (ISO, 2014). Where ring external diameters did not correspond with those stated for diaphragm devices, the distance between the cross-arm and the ring holder was determined by extrapolation or interpolation using the mean external diameter for each ring formulation. The degree of twist (angular rotation, $\pm 5^{\circ}$ ) of the ring during compression was indicated by movement of the pointer on the angular scale away from the starting (zero) position in either a clockwise or anticlockwise direction. The eight vaginal ring types (Table $1 ; \mathrm{n}=13$ rings per formulation) were assessed before and after undergoing the 1000-cycle compression test. 


\section{RESULTS AND DISCUSSION}

\subsection{Characterisation of ring geometry}

Physical characteristics including mean ring weight, CSD and OD for the eight vaginal ring types were recorded (Table 1). Visual inspection revealed that all ring formulations, except NuvaRing ${ }^{\circledR}$, were fully toroidal in shape. NuvaRing ${ }^{\circledR}$ samples were circumferentially ovoid making OD measurement more variable for this particular ring group. All $200 \mathrm{mg}$ DPV and 200/320 mg DPV+LNG rings, manufactured in-house, had a white, opaque appearance consistent with uniform distribution of the solid API powders throughout the transparent elastomer matrix and were free from surface defects.

\subsection{Durometer Hardness Test}

The durometer of the MED-4870 and DDU-4320 silicone elastomer raw materials - used to manufacture the $200 \mathrm{mg}$ DPV and the 200/320 mg DPV+LNG, respectively - were evaluated according to ASTM D2240 (Type A scale). Active batches of MED-4870 with up to $2.5 \%$ w/w DPV and DDU-4320 containing DPV and LNG were tested to observe the effects of API addition to the two silicone systems. A mean Shore A hardness value of $70.67 \pm 0.52$ was obtained for MED-4870 slabs produced under the same conditions as prescribed by the material supplier $\left(165^{\circ} \mathrm{C} / 5 \mathrm{~min}\right)$, indicating that the raw material met the required specification (68-78 Shore A). A value of 69.14 \pm 0.41 was determined for MED-4870 samples cured using typical ring manufacturing conditions $\left(185^{\circ} \mathrm{C} / 60 \mathrm{~s}\right)$; within the required raw material specification. Interestingly, the $0.3125 \% \mathrm{w} / \mathrm{w}$ and $2.5 \% \mathrm{w} / \mathrm{w}$ DPV-loaded MED4870 slab samples produced Shore A hardness values of $62.27 \pm 0.82$ and $62.50 \pm 0.55$, respectively, when cured at $165^{\circ} \mathrm{C}$ for $5 \mathrm{~min}$. This reduction may be attributed to the presence of MED-360 oil and DPV in these formulations. 
The CoA for DDU-4320 states a Shore A hardness value of $16(>15)$ for slab samples cured at $80 \pm 5^{\circ} \mathrm{C}$ for $3 \pm 1 \mathrm{~min}$. A mean Shore A hardness value of $13.83 \pm 0.41$ was obtained for DDU-4320 slabs manufactured in-house under the same conditions. All in-house manufactured test samples were stabilised for $24 \pm 1 \mathrm{hr}$ at ambient temperature and humidity prior to testing. The DPV+LNG slab samples cured under the same conditions as the DDU4320 product specification provided a value of $11.50 \pm 0.55$ Shore A. In this case, the lower durometer value may be attributable to inhibition of the silicone elastomer curing reaction as a result of irreversible covalent binding of the LNG molecules to the addition-cure silicone elastomer system (Murphy et al., 2016).

A similar reduction in hardness was observed for the DPV+LNG VR's cured at $100^{\circ} \mathrm{C}$ for 90 s. Mean Shore A and Shore M hardness results for all VRs tested are presented in Table 2 . The $25 \mathrm{mg}$ DPV formulations produced mean Shore A hardness values ranging from 66.968.5 , slightly lower than the value stated in the MED-4870 product specification. Mean Shore M hardness values for the $25 \mathrm{mg}$ DPV rings ranged from 69.4-70.0. The $200 \mathrm{mg}$ DPV formulation produced similar mean Shore A and Shore M hardness values of $66.58 \pm 0.80$ and $69.85 \pm 0.32$, respectively, despite the increased API loading. The presence of MED-360 silicone oil, along with differences in the DPV loadings, processing parameters and storage times, could account for the variation in hardness values recorded for these formulations. Interestingly, the mean hardness values recorded for all DPV ring formulations lay within the range of the commercially available rings tested.

Mean Shore A and Shore M hardness values recorded for the 200/320 mg DPV+LNG DDU4320 formulation were $28.21 \pm 0.80$ and $29.94 \pm 0.71$, respectively. Although, the specified Shore A hardness for the DDU-4320 silicone elastomer was 16 (arbitrary units), the high API 
loading in this particular ring formulation could, in part, account for the lower hardness values recorded. Although Shore A durometer testing of VRs does not conform to ASTM D2240 (Type A scale) testing standards (due to VR geometries, curved ring surfaces and possible influence of edge effects), it remains a useful investigational tool for rapid comparison of different VRs as well as a simple QC test for incoming materials and VRs. Due to the indenter geometry, Shore M hardness gauges conform to the ASTM D2240 (Type M scale) testing standards, and for certain VR devices could produce more accurate and reproducible results. Durometer testing is an empirical method and there is no direct correlation between shore hardness and any physical material property, such as modulus or strength. However, it does tend to correlate closely with the crosslinking density in elastomeric materials, and to a lesser extent with tensile strength. Its main function is for quality control purposes and, in this context, the Shore M method is deemed most appropriate for VR testing given their geometry.

\subsection{Static 28-day deformation}

Assessment of ring recovery ( 8 formulations; $n=13$ rings per formulation) following prolonged static deformation may provide useful information regarding the long-term viability of a ring device, and particularly the potential for structural failures (weld failures or rupture of sheath layers) over the intended use period. Ring recovery data following 28-day static deformation testing indicated that all rings in the $25 \mathrm{mg}$ DPV MED-4870 ring batches recovered between $90-100 \%$ of their original OD immediately after removal of the compression force (15-20 s after removal of the compression force). Femring ${ }^{\circledR}$ was the only ring product to return to $100 \%$ of its original OD. Estring ${ }^{\circledR}$ and the $200 / 320 \mathrm{mg}$ DPV+LNG ring group recovered $80-100 \%$ of their original measured diameter. NuvaRing ${ }^{\circledR}$, the only thermoplastic ring device evaluated, recovered only 50-60\% of its original OD. The $25 \mathrm{mg}$ 
DPV ring formulations perform similarly to the commercial products Femring ${ }^{\circledR}$ and Estring ${ }^{\circledR}$, and considerably better than NuvaRing ${ }^{\circledR}$, in a side-by-side 28-day static deformation test. The 200/320 mg DPV+LNG ring performs better than NuvaRing ${ }^{\circledR}$ and Estring ${ }^{\circledR}$, but not as well as Femring $^{\circledR}$. Overall, mechanical performance of the experimental rings lies within the range measured for the marketed rings.

VRs are typically designed to remain in vivo for periods of 28 days or longer. Although, many of the currently marketed ring products are designed to remain in place for the entire period of use (up to 1 month), newer long-acting ring products such as the 1-year Annovera $^{\mathrm{TM}}$ contraceptive ring may require multiple removals either for cleaning and/or for storage. Any successful ring device must be able to exert sufficient pressure so as not to be expelled during daily activities while retaining sufficient flexibility so as not to damage the vaginal tissue or cause discomfort to the user. Any significant deformation/lack of full recovery of ring shape due to long term compression may prove problematic and result in ring retention issues. No significant reports of excessive expulsion or vaginal discomfort have been reported for the marketed VR products, and so logically their recovery values are indicative of ring devices suitable for clinical use.

\subsection{Determination of Tensile Properties}

Tensile strength - listed as an attribute on silicone elastomer and thermoplastic product specifications - is the force required to rupture a sample cut from ASTM D412 Die C (ASTM D412 - 16 Standard Test Methods for Vulcanized Rubber and Thermoplastic Elastomers.

Tension, 2016) when stretched longitudinally. In accordance with the requirements set out in ISO 8009:2014, a tensile testing experiment was designed and performed to assess the maximum load required to cause ring fracture and the elongation at break, i.e. maximum 
extension at maximum load for the eight different vaginal ring lots outlined in Table 3.

Maximum load at fracture rather than tensile strength was reported due to the infeasibility of calculation of the actual sample cross sectional area at the time of fracture. A single fracture point was observed for all silicone elastomer devices, with the exception of Femring ${ }^{\circledR}$ which fractured at multiple sites. These multiple fracture points may be due in part to (i) the partial core design of the ring and (ii) the tear strength of the tin-catalysed silicone elastomer used in production of this particular ring formulation. NuvaRing ${ }^{\circledR}$, the only thermoplastic ring formulation tested, stretched and elongated before eventually fracturing at the ring weld site. Table 3 shows that the mean tensile extension at the point of fracture, i.e. maximum load for the three $25 \mathrm{mg}$ DPV ring batches (301-314 mm), was significantly greater than for Femring $^{\circledR}(108 \mathrm{~mm})$ but less than NuvaRing ${ }^{\circledR}$ (392 mm) and Estring ${ }^{\circledR}$ (549 mm). The mean maximum load at maximum extension for the three $25 \mathrm{mg}$ DPV batches $(666-684 \mathrm{~N})$ was higher than that achieved for Femring ${ }^{\circledR}$ and NuvaRing ${ }^{\circledR}$ (271 N and $137 \mathrm{~N}$, respectively) and only slightly lower than that recorded for Estring ${ }^{\circledR}$ (701 N). The 200/320 mg DPV+LNG ring formulation endured a tensile load of $69 \mathrm{~N}$ before fracture and extended to $145 \mathrm{~mm}$ before failure; here, the tensile load is lower than for other rings tested and the extension is similar to values measured for NuvaRing ${ }^{\circledR}$. With the exception of the 200/320 mg DPV+LNG ring, all other ring types withstood higher loads than those previously reported for women using a single finger under ideal conditions to pull a solidly-fixed rigid ring (Cort and Potvin, 2011).

Mean percentage elongation at break values for each ring group (Table 3) showed that for the three $25 \mathrm{mg}$ DPV ring batches, the values ranged from 751 to $783 \%$. Mean percentage elongation at break values of $571 \%$ and $354 \%$ were recorded for the $200 \mathrm{mg}$ DPV MED-4870 and 200/320 mg DPV+LNG rings, respectively. Mean percent elongation at break values for all DPV-only and DPV+LNG ring formulations were greater than for Femring ${ }^{\circledR}$ (263\%) but 
less than both NuvaRing ${ }^{\circledR}(824 \%)$ and Estring ${ }^{\circledR}(1511 \%)$. Overall, the DPV and DPV+LNG ring formulation elongation results lie within the range of the commercially available rings that were tested. Tensile testing is particularly important for vaginal ring products that contain a weld site or more complicated ring designs that contain drug-loaded reservoirs or inserts. Ring products containing weld joints, such as NuvaRing ${ }^{\circledR}$, have the potential to rupture when placed under excessive force or as a result of changes to the ring manufacturing process (manufacturing materials and joint welding equipment). Simple tensile testing protocols can be used to assess weld joint integrity as part of the quality control process.

\subsection{0-Cycle Compression Test}

On completion of the thousandth compression cycle, the three $25 \mathrm{mg}$ DPV ring batches, the $200 \mathrm{mg}$ DPV ring, the 200/320 mg DPV+LNG and the Femring ${ }^{\circledR}$ samples showed no visible signs of deterioration and returned to $100 \%$ of their original OD within 15 min of test completion. By comparison, the NuvaRing ${ }^{\circledR}$ devices were visibly deformed and recovered only $80 \%$ of the original OD within the same time period. In ISO8009:2014 (ISO, 2014), the acceptance criteria for diaphragm devices was set as at least $90 \%$ recovery of original OD on removal of the thousandth cycle compression force. All ring formulations except NuvaRing ${ }^{\circledR}$ met this acceptance criterion. However, as previously discussed, the acceptance limits set for diaphragm devices are not necessarily applicable to vaginal ring devices due to the inherent differences in construction, their higher degree of flexibility, and the fact that placement of a vaginal ring in the vaginal cavity is not designed to create a physical barrier function at the cervix. Furthermore, unlike diaphragm devices, VRs may be retained in a state of compression within the vaginal cavity following insertion.

\subsection{Twisting During Compression}


The data presented in Table 4 indicates that the $25 \mathrm{mg}$ DPV, $200 \mathrm{mg}$ DPV, Femring ${ }^{\circledR}$, Estring $^{\circledR}$ and 200/320 mg DPV+LNG silicone elastomer VRs were easily twisted, producing angular rotations/degrees of twist between $50-75^{\circ}$ and with no visual evidence of permanent deformation. This is not surprising, given the highly elastic nature of silicone elastomers. By comparison, the extent of twist achieved by NuvaRing ${ }^{\circledR}$ devices was much lower, ranging from $0-5^{\circ}$, with no recovery to their original OD on removal of the compression force. Due to the ovoid circumference and subsequent variability in OD, NuvaRing ${ }^{\circledR}$ samples were consistently orientated in the twist jig so that the ring weld joint was in contact with the upper plate. Testing of the silicone elastomer ring groups following the 1000-cycle compression test produced angular rotations in the range of $45-85^{\circ}$. No evidence of permanent distortion was observed. Following the 1000-cycle compression test, NuvaRing ${ }^{\circledR}$ devices did not fully recover their original OD ( $80 \%$ recovery of OD within $15 \mathrm{~min}$ of the test completion). Therefore, they differed in OD when compared to untested rings and were distinctly ovoid in shape. The angular rotation observed for NuvaRing ${ }^{\circledR}$ samples following the 1000-cycle compression test ranged from $0-40^{\circ}$ compared to $0-5^{\circ}$ for rings tested as supplied.

Similarities in the range of angular rotations observed for the different silicone elastomerbased ring formulations indicate that the discriminating power of the "twist during compression' test for this type of ring device is limited. The data also indicates that the 1000 cycle compression test had little or no impact on the degree of twist observed for silicone elastomer ring samples with similar angular rotation ranges observed for rings pre- and post1000 cycle compression testing. This suggests that where the material is fully elastic, the ring geometry is the most significant contributory factor in the amount of twist observed. For NuvaRing ${ }^{\circledR}$, a larger angular rotation range was observed for rings post-1000 cycle compared to as supplied rings. Significant changes in the outer diameter of the NuvaRing ${ }^{\circledR}$ as a result of 
the 1000-cycle compression testing is the most likely cause of this difference. ISO 8009:2014 (ISO, 2014) requires that twisting during compression be assessed for all diaphragm devices to ensure that the devices are not significantly deformed by compressional forces similar to those exerted during insertion of the device. This is a critical consideration for diaphragms as significant twisting can cause permanent deformation of the device thereby reducing the effectiveness of these barrier contraceptive devices. Specifically, the standard states that the extent of twist for a diaphragm should be no more than $20^{\circ}$, however, a $20^{\circ}$ acceptance limit is not relevant for VRs due to their elastomeric nature, toroidal shape and higher degree of flexibility. In contrast to diaphragms, placement of a VR in the vagina is often facilitated by compressing them into a twisted 'figure-8' and they are not intended to create a physical barrier to the cervix. Furthermore, VRs do not contain the dome/cap, cup, and wire spring portions of the diaphragm device responsible for limiting flexibility. Based on the significantly broad range of results obtained, the authors were unable to correlate this test result with a specific performance criterion related to the function of VR devices, concluding that the recording of twisting during compression may be limited in relevancy for VRs.

\section{CONCLUSIONS}

Mechanical testing protocols were developed for VR devices based on the methods described in ISO8009:2014, though the tests and associated failure criteria specified in this standard are based around the requirement for testing of diaphragms that must function as barrier contraceptive devices. Our revised testing protocols were adapted for the geometrical requirements of drug releasing vaginal rings and applied to longstanding marketed VRs and a number of investigational formulations from the International Partnership for Microbicide. The final test protocols included; assessment of cross sectional and outer diameters, durometer hardness testing of a ring laid flat in the horizontal plane, compression of the ring 
to $25 \%$ of its original diameter either statically for 28 days or dynamically for one thousand cycles, destructive tensile testing and recording of the angular twist during compression of the VR. All of the tests developed were considered to provide data that would be pertinent in ring design, development and/or quality control with the exception of the angular twist test, which was deemed not meaningful to mechanical performance of the VRs. Acceptance criteria were not developed as part of this work and functional performance criteria for vaginal ring products have yet to be established. Further work will be required in the correlation of mechanical test parameters with in-vivo VR device function. Through comparative analysis, IPM's investigational VR formulations recorded similar mechanical test results to those of the marketed VRs that were tested. 


\section{ACKNOWLEDGEMENTS}

The work was supported by a grant to Queen's University Belfast from the International Partnership for Microbicides, through the generous support from the Ministry of Foreign Affairs of the Netherlands and the American people through the United States Agency for International Development (USAID) in partnership with the President's Emergency Plan for AIDS Relief (PEPFAR).

\section{AUTHOR INFORMATION}

\section{Corresponding Author}

* Peter Boyd, School of Pharmacy, Medical Biology Centre, Queen's University Belfast, Belfast BT9 7BL, United Kingdom. Tel: +44 (0)28 9097 2623. E-mail: p.boyd@qub.ac.uk

\section{Declaration of Interest}

The authors declare no competing financial or personal interest.

\section{Author Contribution Statement}

P.B., K.M. and B.D. contributed to funding acquisition. P.B., C.M., B.M., K.M., D.M and W.B. conceived and planned the experiments. C.M., B.M. and P.B. carried out the experiments. D.M. and C.M. contributed to sample preparation. All authors contributed to the interpretation of the results. P.B. and C.M. took the lead in writing the manuscript. All authors provided critical feedback and helped shape the research, analysis and manuscript. 


\section{REFERENCES}

ASTM D2240-15e1, Standard Test Method for Rubber Property — Durometer Hardness, 2015. https://doi.org/10.1520/D2240-15E01

ASTM D412 - 16 Standard Test Methods for Vulcanized Rubber and Thermoplastic

Elastomers. Tension, 2016. . ASTM. https://doi.org/10.1520/D0412-16

Baah-Dwomoh, A., McGuire, J., Tan, T., De Vita, R., 2016. Mechanical Properties of Female Reproductive Organs and Supporting Connective Tissues: A Review of the Current State of Knowledge. Appl. Mech. Rev. 68, 060801. https://doi.org/10.1115/1.4034442

Bash, K.L., 2000. Review of Vaginal Pessaries. Obstet. Gynecol. Surv. 55.

Baum, M.M., Butkyavichene, I., Gilman, J., Kennedy, S., Kopin, E., Malone, A.M., Nguyen, C., Smith, T.J., Friend, D.R., Clark, M.R., Moss, J. a., 2012. An intravaginal ring for the simultaneous delivery of multiple drugs. J. Pharm. Sci. 101, 2833-2843.

https://doi.org/10.1002/jps.23208

Bisplinghoff, J.A., Kemper, A.R., Duma, S.M., 2012. Dynamic material properties of the pregnant human uterus. J. Biomech. 45, 1724-1727. https://doi.org/10.1016/j.jbiomech.2012.04.001

Boyd, P., Fetherston, S.M., McCoy, C.F., Major, I., Murphy, D.J., Kumar, S., Holt, J., Brimer, A., Blanda, W., Devlin, B., Malcolm, R.K., 2016. Matrix and reservoir-type multipurpose vaginal rings for controlled release of dapivirine and levonorgestrel. Int. J. Pharm. 511, 619-629. https://doi.org/10.1016/j.ijpharm.2016.07.051

Chantereau, P., Brieu, M., Kammal, M., Farthmann, J., Gabriel, B., Cosson, M., 2014. Mechanical properties of pelvic soft tissue of young women and impact of aging. Int. Urogynecol. J. Pelvic Floor Dysfunct. 25, 1547-1553. https://doi.org/10.1007/s00192$014-2439-1$ 
Clark, J.T., Clark, M.R., Shelke, N.B., Johnson, T.J., Smith, E.M., Andreasen, A.K., Nebeker, J.S., Fabian, J., Friend, D.R., Kiser, P.F., 2014. Engineering a segmented dualreservoir polyurethane intravaginal ring for simultaneous prevention of HIV transmission and unwanted pregnancy. PLoS One 9, e88509. https://doi.org/10.1371/journal.pone.0088509

Clark, J.T., Johnson, T.J., Clark, M.R., Nebeker, J.S., Fabian, J., Tuitupou, A.L., Ponnapalli, S., Smith, E.M., Friend, D.R., Kiser, P.F., 2012. Quantitative evaluation of a hydrophilic matrix intravaginal ring for the sustained delivery of tenofovir. J. Control. Release 163, 240-248. https://doi.org/10.1016/j.jconrel.2012.08.033

Conrad, J.T., Johnson, W.L., Kuhn, W.K., Hunter Jr., C.A., 2017. Passive stretch relationships in human uterine muscle. Am. J. Obstet. Gynecol. 96, 1055-1059. https://doi.org/10.1016/0002-9378(66)90513-8

Cort, J.A., Potvin, J.R., 2011. Maximum isometric finger pull forces. Int. J. Ind. Ergon. 41, 91-95. https://doi.org/10.1016/j.ergon.2010.12.008

Eberhart, R., Chuong, C.-J., Zimmern, P., 2017. Exploring biomechanical methods to study the human vaginal wall. Neurourol. Urodyn. 36, 499-506. https://doi.org/10.1002/nau.22968

FDA, U. (Dept of H. and H.S., 2014. Guidance for Industry Vaginal Microbicides : Development for the Prevention of HIV Infection Guidance for Industry Vaginal Microbicides : Development for the Prevention of HIV Infection. https://www.fda.gov/downloads/drugs/guidances/ucm328842.pdf - last accessed, 23 December 2018.

Fetherston, S.M., Boyd, P., McCoy, C.F., McBride, M.C., Edwards, K.-L.L., Ampofo, S., Malcolm, R.K., 2013a. A silicone elastomer vaginal ring for HIV prevention containing two microbicides with different mechanisms of action. Eur. J. Pharm. Sci. 48, 406-415. https://doi.org/10.1016/j.ejps.2012.12.002 
Fetherston, S.M., Boyd, P., McCoy, C.F., McBride, M.C., Edwards, K.L., Ampofo, S., Malcolm, R.K., 2013b. A silicone elastomer vaginal ring for HIV prevention containing two microbicides with different mechanisms of action. Eur. J. Pharm. Sci. 48, 406-415. https://doi.org/10.1016/j.ejps.2012.12.002

Friend, D.R., 2011. Intravaginal rings: Controlled release systems for contraception and prevention of transmission of sexually transmitted infections. Drug Deliv. Transl. Res. 1, 185-193. https://doi.org/10.1007/s13346-011-0024-4

ISO, 2014. ISO 8009:2014(E) Mechanical contraceptives — Reusable natural and silicone rubber contraceptive diaphragms - Requirements and tests, ISO Standard. International Organization for Standards, Geneva.

Jean-Charles, C., Rubod, C., Brieu, M., Boukerrou, M., Fasel, J., Cosson, M., 2010.

Biomechanical properties of prolapsed or non-prolapsed vaginal tissue: Impact on genital prolapse surgery. Int. Urogynecol. J. 21, 1535-1538.

https://doi.org/10.1007/s00192-010-1208-z

Johnson, T.J., Clark, M.R., Albright, T.H., Nebeker, J.S., Tuitupou, A.L., Clark, J.T., Fabian, J., McCabe, R.T., Chandra, N., Doncel, G.F., Friend, D.R., Kiser, P.F., 2012. A 90-day tenofovir reservoir intravaginal ring for mucosal HIV prophylaxis. Antimicrob. Agents Chemother. 56, 6272-6283. https://doi.org/10.1128/AAC.01431-12

Johnson, T.J., Gupta, K.M., Fabian, J., Albright, T.H., Kiser, P.F., 2010. Segmented polyurethane intravaginal rings for the sustained combined delivery of antiretroviral agents dapivirine and tenofovir. Eur. J. Pharm. Sci. 39, 203-12. https://doi.org/10.1016/j.ejps.2009.11.007

Kim, J.H., 2015. Urogynecology and Reconstructive Pelvic Surgery. 4th ed. Int. Neurourol. J. 19, 51-51. https://doi.org/10.5213/inj.2015.19.1.51

Malcolm, R.K., Boyd, P.J., Mccoy, C.F., Murphy, D.J., 2016. Microbicide vaginal rings : Technological challenges and clinical development. Adv. Drug Deliv. Rev. 103, 33-56. 
https://doi.org/10.1016/j.addr.2016.01.015

Malcolm, R.K., Fetherston, S.M., McCoy, C.F., Boyd, P., Major, I., 2012. Vaginal rings for delivery of HIV microbicides. Int. J. Womens. Health 4, 595-605. https://doi.org/10.2147/IJWH.S36282

Moss, J.A., Butkyavichene, I., Churchman, S.A., Gunawardana, M., Fanter, R., Miller, C.S., Yang, F., Easley, J.T., Marzinke, M.A., Hendrix, C.W., Smith, T.J., Baum, M.M., 2016. Combination pod-intravaginal ring delivers antiretroviral agents for HIV prophylaxis: Pharmacokinetic evaluation in an ovine model. Antimicrob. Agents Chemother. 60, 3759-3766. https://doi.org/10.1128/AAC.00391-16

Murphy, D.J., Boyd, P., McCoy, C.F., Kumar, S., Holt, J.D.S., Blanda, W., Brimer, A.N., Malcolm, R.K., 2016. Controlling levonorgestrel binding and release in a multi-purpose prevention technology vaginal ring device. J. Control. Release 226, 138-147. https://doi.org/10.1016/j.jconrel.2016.02.020

Owen, D.H., Katz, D.F., 1999. A vaginal fluid simulant. Contraception 59, 91-5.

Pathak, M., Turner, M., Palmer, C., Coombes, A.G. a, 2014. Evaluation of polycaprolactone matrices for the intravaginal delivery of metronidazole in the treatment of bacterial vaginosis. J. Biomater. Appl. 29, 354-63. https://doi.org/10.1177/0885328214528256

Rahn, D.D., Ruff, M.D., Brown, S.A., Tibbals, H.F., Word, R.A., 2008. Biomechanical properties of the vaginal wall: effect of pregnancy, elastic fiber deficiency, and pelvic organ prolapse. Am. J. Obstet. Gynecol. 198. https://doi.org/10.1016/j.ajog.2008.02.022

Rubod, C., Boukerrou, M., Rousseau, J., Viard, R., Brieu, M., Dubois, P., 2006. A biomechanical model of the pelvic cavity: First steps. Annu. Int. Conf. IEEE Eng. Med. Biol. - Proc. 968-971. https://doi.org/10.1109/IEMBS.2006.260236

Ugaonkar, S.R., Wesenberg, A., Wilk, J., Seidor, S., Mizenina, O., Kizima, L., Rodriguez, A., Zhang, S., Levendosky, K., Kenney, J., Aravantinou, M., Derby, N., Grasperge, B., Gettie, A., Blanchard, J., Kumar, N., Roberts, K., Robbiani, M., Fernández-Romero, J. 
a., Zydowsky, T.M., 2015. A novel intravaginal ring to prevent HIV-1, HSV-2, HPV, and unintended pregnancy. J. Control. Release 213, 57-68. https://doi.org/10.1016/j.jconrel.2015.06.018

Vincent, K.L., Moss, J.A., Marzinke, M.A., Hendrix, C.W., Anton, P.A., Pyles, R.B., Guthrie, K.M., Dawson, L., Olive, T.J., Butkyavichene, I., Churchman, S.A., Cortez, J.M., Fanter, R., Gunawardana, M., Miller, C.S., Yang, F., Rosen, R.K., Vargas, S.E., Baum, M.M., 2018. Safety and pharmacokinetics of single, dual, and triple antiretroviral drug formulations delivered by pod-intravaginal rings designed for HIV-1 prevention: A Phase I trial. PLOS Med. 15, e1002655. https://doi.org/10.1371/journal.pmed.1002655

Wang, Y., Boyd, P., Hunter, A., Malcolm, R.K., 2018. Intravaginal rings for continuous lowdose administration of cervical ripening agents. Int. J. Pharm. 549, 124-132. https://doi.org/10.1016/j.ijpharm.2018.07.053 


\section{FIGURE CAPTIONS}

Fig. 1. Mold design for durometer testing of MED-4870 slab. All dimensions are in mm.

Fig. 2. Custom 28-day compression jig showing: (A) 200/320 mg DPV+LNG ring prior to compression; (B) 25 mg DPV ring under compression; (C) NuvaRing ${ }^{\circledR}$ compressed to $25 \%$ of its original diameter; (D) multiple ring sets under compression.

Fig. 3. Example of a ring recovery gauge (A) measuring $\%$ recovery in terms in $\%$ of original outer diameter for each of the different ring batches. (B) Gauge with 200/320 mg DPV+LNG ring showing 100\% recovery.

Fig. 4. (A) Tensile testing jig with ring inserted. (B) Schematic of the tensile testing jig used to determine elongation at break. All dimensions in mm unless stated. $48 \mathrm{~mm}$ is an exemplar value, pin spacing was dependent on specific ring geometry.

Fig. 5. Representative images of the custom manufacture 1000-cycle compression jig containing $200 \mathrm{mg}$ DPV rings uncompressed (A) and compressed (B). (C) Multiple Nuvaring placed in jig prior to start of test and (D) in their fully compressed state.

Fig. 6. Custom twist jig measuring angular rotation range during compression within a $5^{\circ}$ interval. (A) base plate only, and (B) jig in use with a ring inserted and compressed. 
Table 1. Ring batch details.

\begin{tabular}{lllll}
\hline Ring Type & Polymer \& Ring Design & $\begin{array}{l}\text { Ring Weight } \\
( \pm \text { SD })(\mathrm{g})\end{array}$ & $\begin{array}{l}\text { Ring OD } \\
( \pm \text { SD })(\mathrm{mm})\end{array}$ & $\begin{array}{l}\text { Ring CSD } \\
( \pm \mathrm{SD})(\mathrm{mm})\end{array}$ \\
\hline $25 \mathrm{mg}$ DPV (NK513) & Addition-cure SE matrix-type & $8.05( \pm 0.03)$ & $55.53( \pm 0.09)$ & $7.76( \pm 0.05)$ \\
$25 \mathrm{mg}$ DPV (RF599) & Addition-cure SE matrix-type & $8.06( \pm 0.02)$ & $55.59( \pm 0.09)$ & $7.78( \pm 0.05)$ \\
$25 \mathrm{mg}$ DPV (SC521) & Addition-cure SE matrix-type & $8.05( \pm 0.02)$ & $55.54( \pm 0.05)$ & $7.78( \pm 0.04)$ \\
$200 \mathrm{mg}$ DPV & Addition-cure SE matrix-type & $8.12( \pm 0.06)$ & $56.24( \pm 0.19)$ & $7.65( \pm 0.04)$ \\
Femring $^{\circledR}$ & Condensation-cure SE reservoir-type & $7.55( \pm 0.06)$ & $56.28( \pm 0.18)$ & $7.54( \pm 0.05)$ \\
NuvaRing $^{\circledR}$ & PEVA reservoir-type & $1.87( \pm 0.01)$ & $55.51( \pm 0.34)$ & $4.02( \pm 0.02)$ \\
Estring $^{\circledR}$ & Addition-cure SE reservoir-type & $9.70( \pm 0.08)$ & $54.20( \pm 0.17)$ & $8.97( \pm 0.11)$ \\
$200 / 320 \mathrm{mg}$ DPV+LNG & Addition-cure SE matrix-type & $7.79( \pm 0.07)$ & $56.50( \pm 0.45)$ & $7.77( \pm 0.09)$ \\
\hline
\end{tabular}

OD: Outer diameter; CSD: Cross sectional diameter; SE: silicone elastomer; PEVA: polyethylene vinyl acetate 
Table 2. Mean Shore A and Shore $M$ hardness measurement for a range of vaginal ring formulations ( $\mathrm{n}=13$ rings per formulation)

\begin{tabular}{lcc}
\hline Ring Batch & $\begin{array}{c}\text { Mean Shore A Hardness } \\
( \pm \text { SD }) \text { (Arb. Units })\end{array}$ & $\begin{array}{c}\text { Mean Shore M Hardness } \\
( \pm \text { SD }) \text { (Arb. Units })\end{array}$ \\
\hline 25 mg DPV (NK513) & $67.19( \pm 0.65)$ & $69.39( \pm 0.72)$ \\
$25 \mathrm{mg}$ DPV (RF599) & $66.92( \pm 0.50)$ & $69.60( \pm 0.34)$ \\
$25 \mathrm{mg}$ DPV (SC521) & $68.54( \pm 0.78)$ & $69.96( \pm 0.30)$ \\
$200 \mathrm{mg}$ DPV & $66.58( \pm 0.80)$ & $69.85( \pm 0.32)$ \\
Femring $^{\circledR}$ & $54.85( \pm 0.73)$ & $59.79( \pm 0.54)$ \\
NuvaRing $^{\circledR}$ & $83.29( \pm 0.69)$ & $89.26( \pm 0.29)$ \\
Estring $^{\circledR}$ & $49.60( \pm 0.51)$ & $53.74( \pm 0.67)$ \\
$200 / 320 \mathrm{mg}$ DPV+LNG & $28.21( \pm 0.80)$ & $29.94( \pm 0.71)$ \\
\hline
\end{tabular}


Table 3. Mean Tensile Extension at Maximum Load, Mean Maximum Load at Maximum Extension and Mean Percentage Elongation at Break data for each vaginal ring formulation ( $n=13$ rings per formulation).

\begin{tabular}{l|l|l|l}
\hline Ring Type & $\begin{array}{l}\text { Mean Tensile } \\
\text { Extension at Max. } \\
\text { Load }( \pm \text { SD) }(\mathrm{mm})\end{array}$ & $\begin{array}{l}\text { Mean Max. Load } \\
\text { at Max. Extension } \\
( \pm \mathrm{SD})(\mathrm{N})\end{array}$ & $\begin{array}{l}\text { Mean elongation } \\
\text { at break }(\%)\end{array}$ \\
\hline $25 \mathrm{mg}$ DPV (NK513) & $301.10( \pm 17.72)$ & $665.64( \pm 35.95)$ & $750.78( \pm 44.69)$ \\
$25 \mathrm{mg}$ DPV (RF599) & $313.94( \pm 19.48)$ & $680.78( \pm 43.41)$ & $782.97( \pm 47.67)$ \\
$25 \mathrm{mg}$ DPV (SC521) & $304.26( \pm 16.67)$ & $684.40( \pm 37.26)$ & $760.82( \pm 41.93)$ \\
$200 \mathrm{mg}$ DPV & $232.97( \pm 19.31)$ & $517.46( \pm 42.77)$ & $571.01( \pm 48.68)$ \\
Femring $^{\circledR}$ & $108.06( \pm 9.14)$ & $271.07( \pm 25.99)$ & $262.85( \pm 21.75)$ \\
NuvaRing $^{\circledR}$ & $391.58( \pm 13.00)$ & $136.99( \pm 2.91)$ & $823.79( \pm 30.52)$ \\
Estring $^{\circledR}$ & $548.52( \pm 11.51)$ & $700.65( \pm 28.79)$ & $1510.99( \pm 30.11)$ \\
200/320 mg DPV+LNG & $144.92( \pm 17.61)$ & $68.93( \pm 23.35)$ & $354.11( \pm 43.09)$ \\
\hline
\end{tabular}


Table 4. Summary of angular rotation from zero $\left(^{\circ}\right)$ (degree of twist) recorded during twist testing of vaginal rings. Rotation measurement dial graduated in $5^{\circ}$ increments.

\begin{tabular}{lll}
\hline Ring Batch & $\begin{array}{l}\text { Angular rotation range } \\
\text { for rings as supplied }\left(^{\circ}\right)\end{array}$ & $\begin{array}{l}\text { Angular rotation range } \\
\text { for rings post-1000 cycle } \\
\text { compression testing }\left(^{\circ}\right)\end{array}$ \\
\hline $25 \mathrm{mg}$ DPV (NK513) & $50-60$ & $45-60$ \\
$25 \mathrm{mg}$ DPV (RF599) & $50-65$ & $50-60$ \\
$25 \mathrm{mg}$ DPV (SC521) & $50-65$ & $50-60$ \\
$200 \mathrm{mg} \mathrm{DPV}$ & $55-65$ & $55-65$ \\
Femring $^{\circledR}$ & $65-70$ & $60-70$ \\
NuvaRing $^{\circledR}$ & $0-5$ & $0-40$ \\
Estring $^{\circledR}$ & $55-70$ & $55-70$ \\
200/320 mg DPV+LNG & $50-75$ & $65-85$ \\
\hline
\end{tabular}




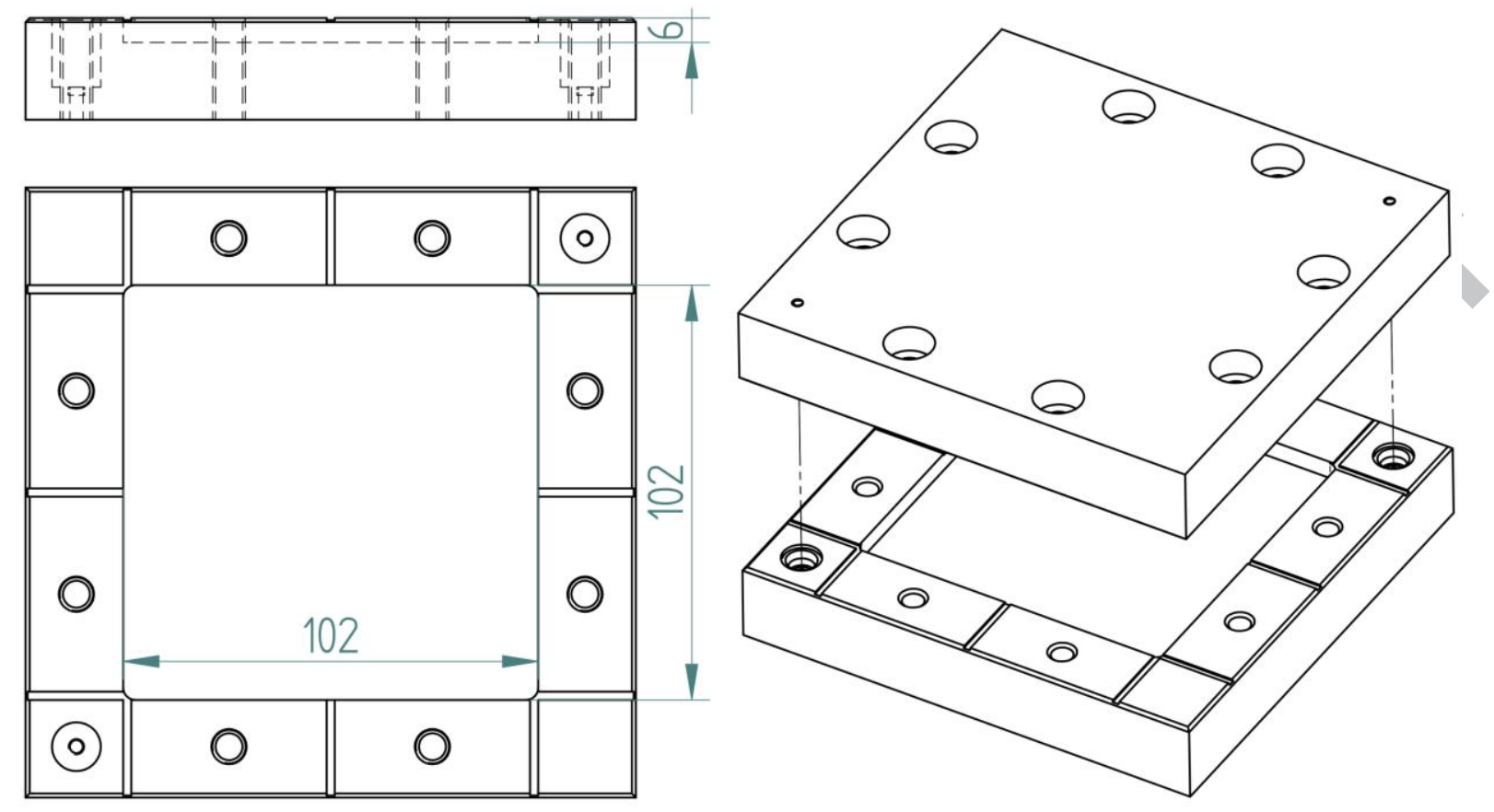


A

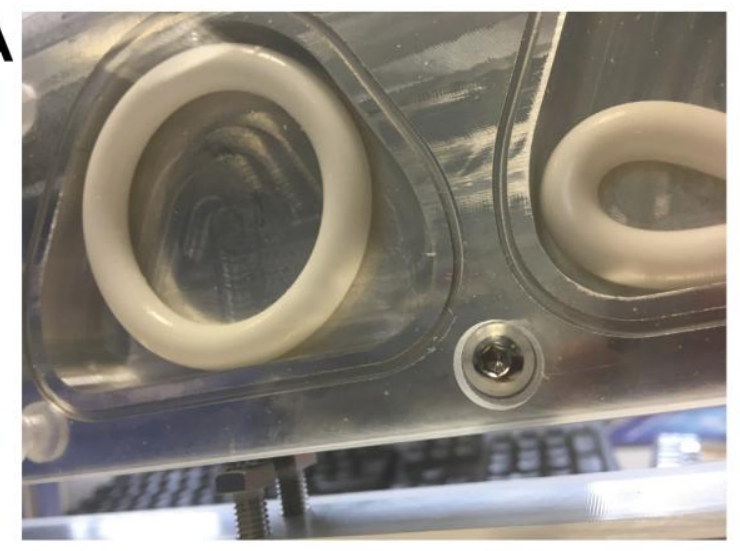

C

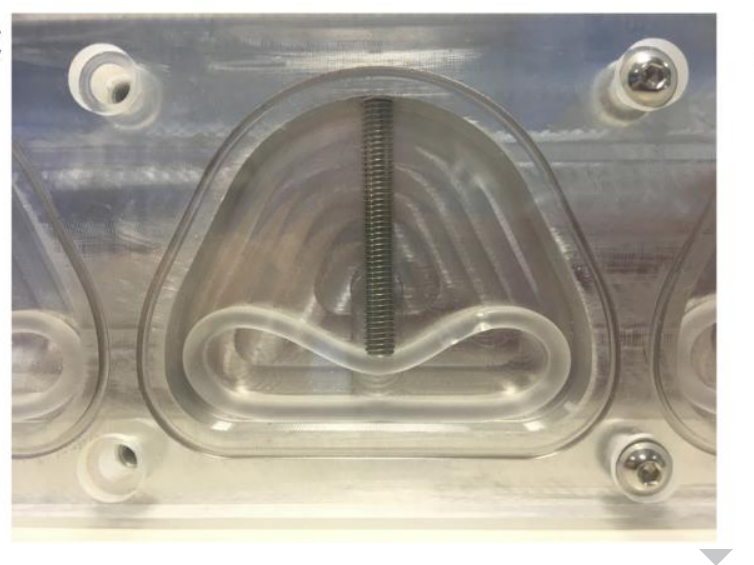

B
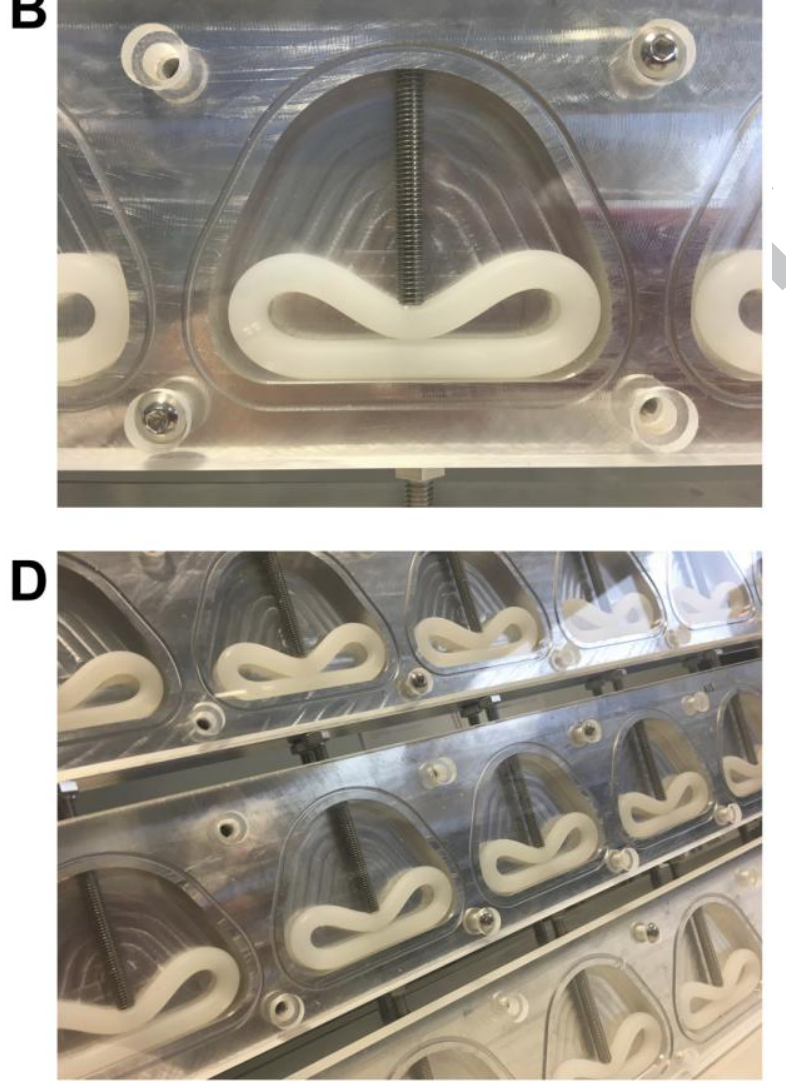

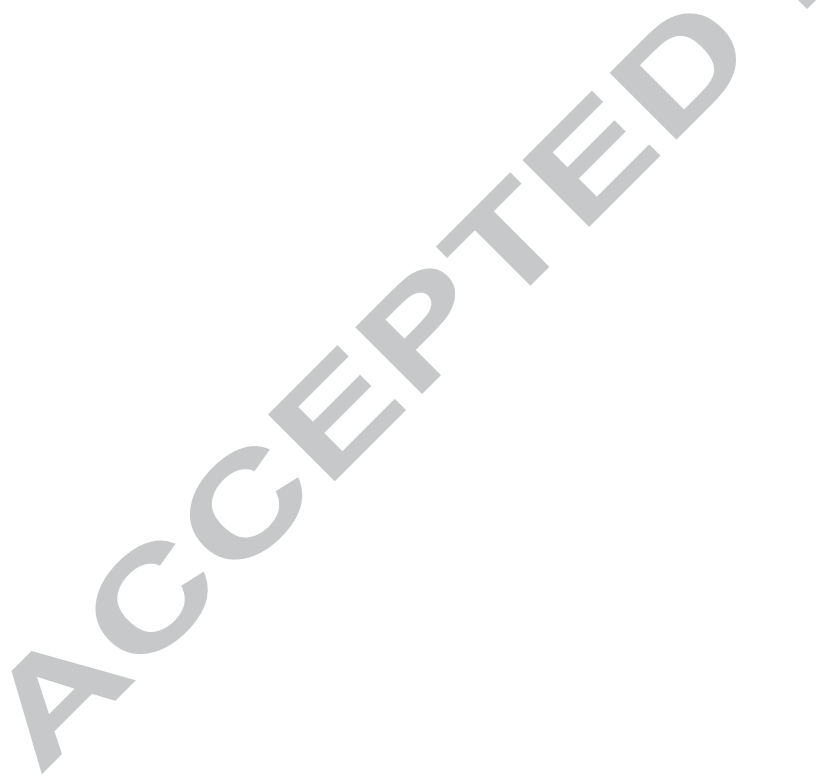




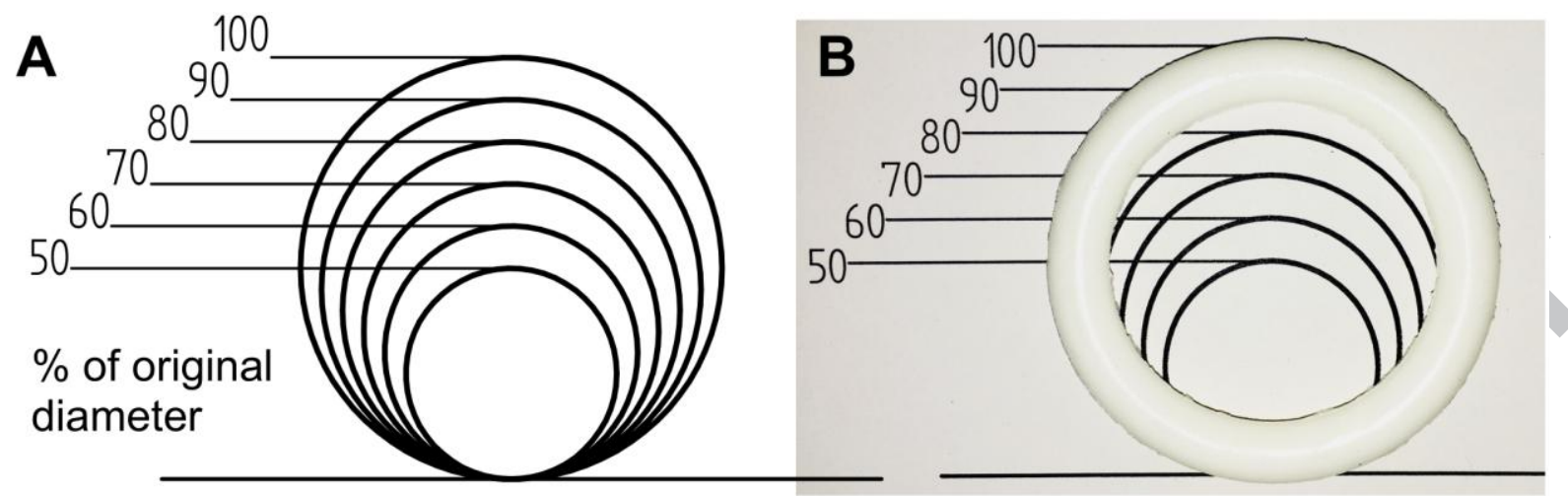




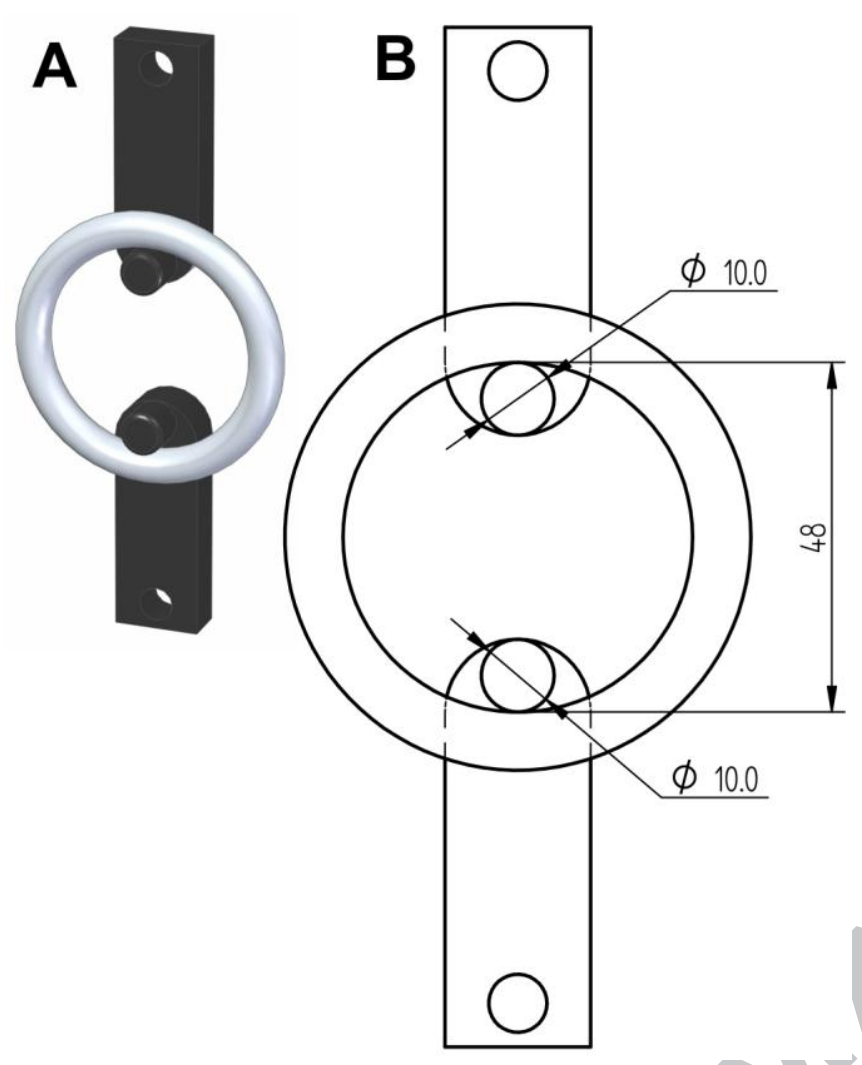



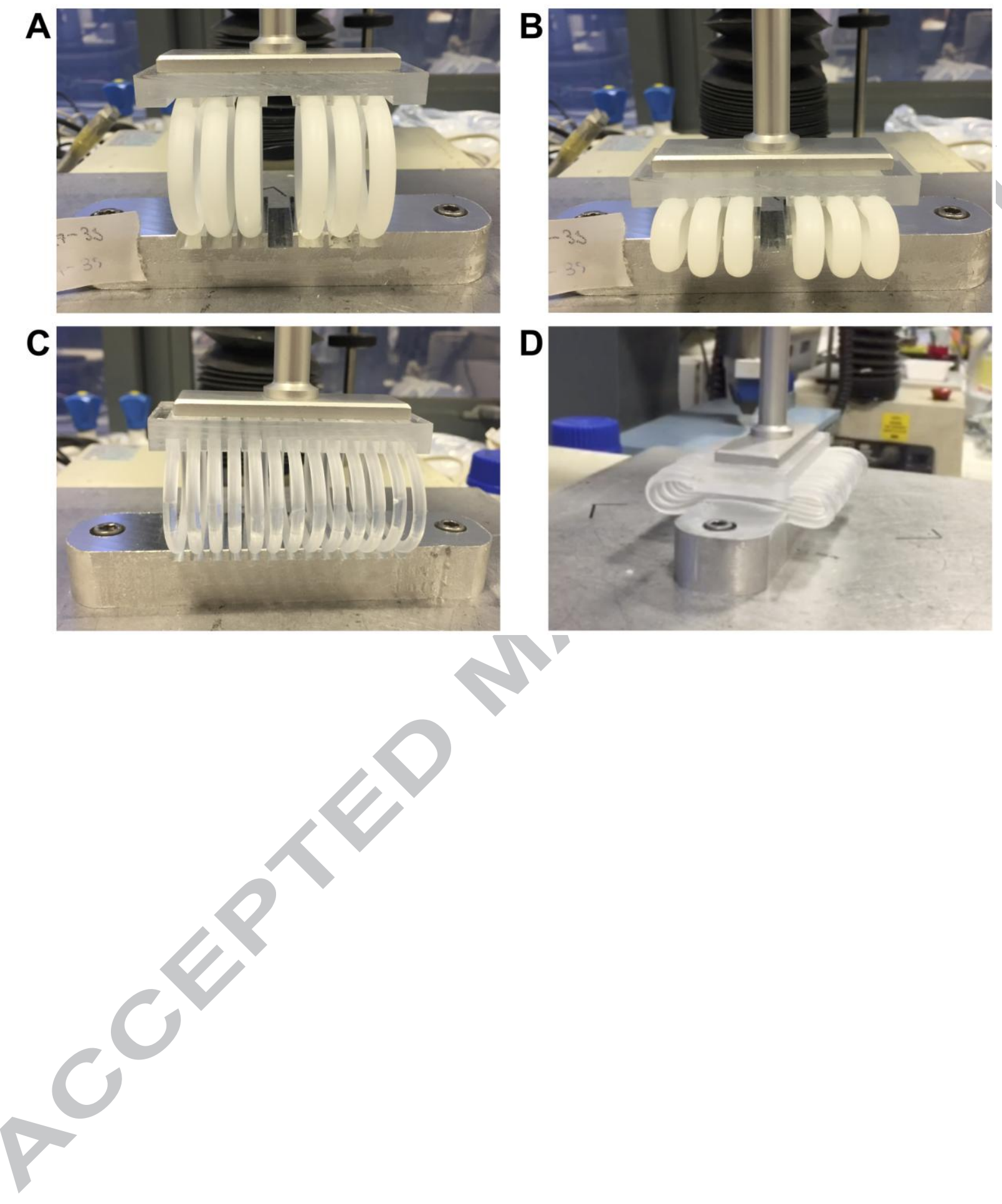


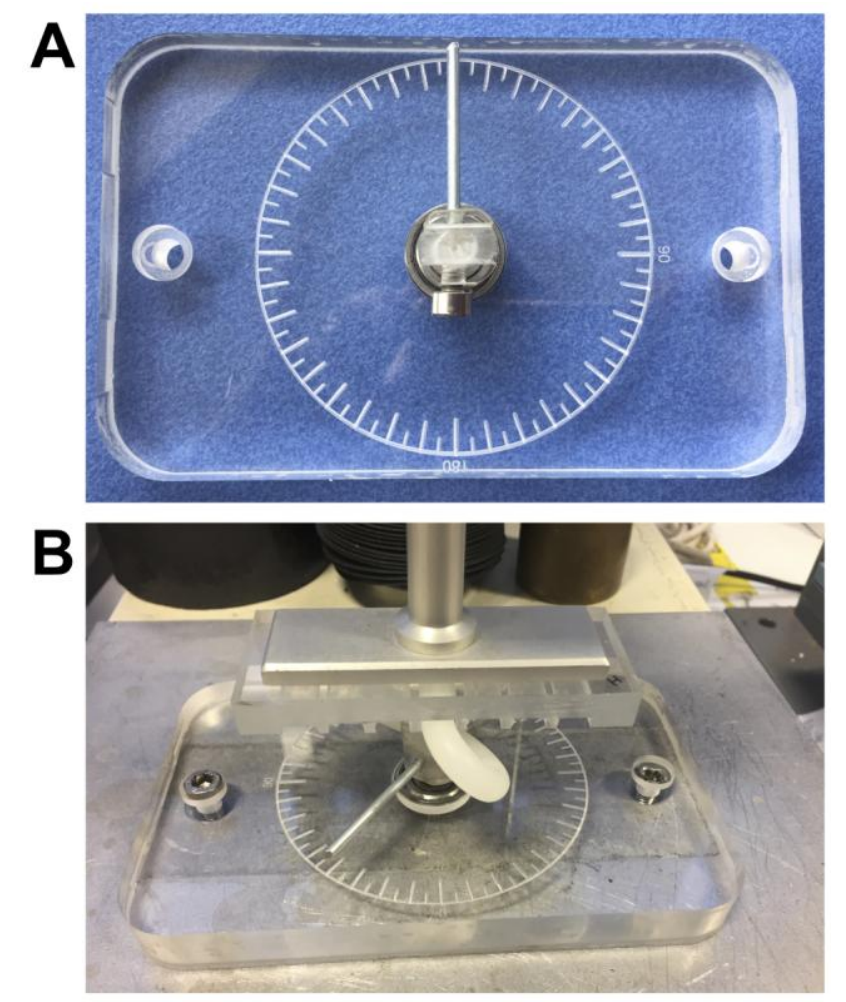




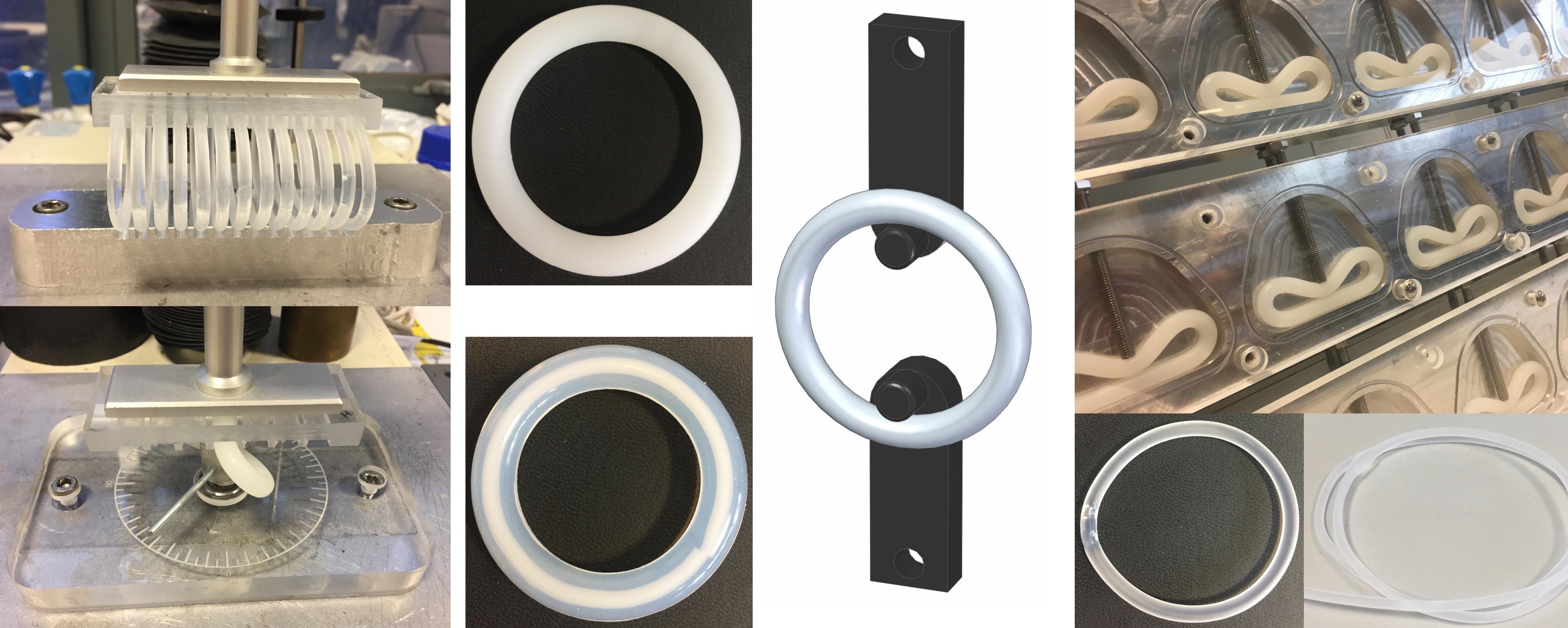

